\title{
Dynamical properties of water in living cells
}

\author{
Irina Piazza ${ }^{1,2, \dagger}$, Antonio Cupane ${ }^{1}$, Emmanuel L. Barbier ${ }^{3,4}$, Claire Rome ${ }^{3,4}$, Nora Collomb ${ }^{3,4}$, \\ Jacques Ollivier ${ }^{2}$, Miguel A. Gonzalez ${ }^{2}$, Francesca Natali ${ }^{5,2, \ddagger}$ \\ ${ }^{1}$ Dept. of Physics and Chemistry, University of Palermo, Viale delle Scienze Ed. 18, 90122 Palermo, Italy \\ ${ }^{2}$ Institut Laue-Langevin, 71 avenue des Martyrs, 38042 Grenoble Cedex 9, France \\ ${ }^{3}$ Institut des Neurosciences, Université Grenoble-Alpes, 38044 Grenoble, France \\ ${ }^{4}$ Inserm, U1216, Grenoble, France \\ ${ }^{5}$ CNR-IOM, OGG, 6 rue Jules Horowitz, 38042 Grenoble Cedex 9, France \\ Corresponding authors. E-mail: ${ }^{\dagger}$ piazzai@ill.fr, ${ }^{\ddagger}$ natali@ill.fr \\ Received November 16, 2017; accepted November17, 2017
}

Erratum to: Front. Phys. 13(1), 138301 (2018)

https://doi.org/10.1007/s11467-017-0731-5

In the original publication of the article, the label $Q^{2}\left(\mathrm{~A}^{-2}\right)$ in Fig. 4 should be replaced with $Q\left(\mathrm{~A}^{-1}\right)$. Below is the correct Fig. 4.

(a)

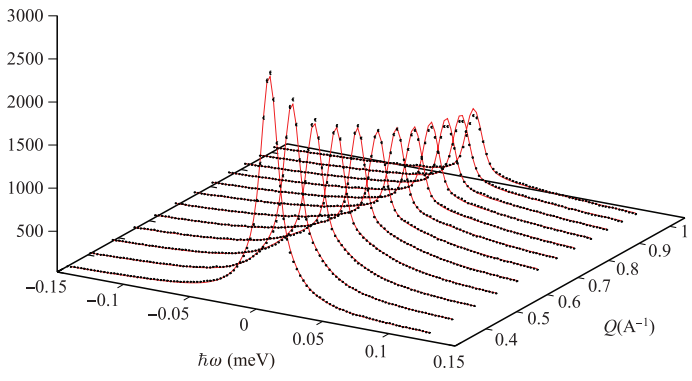

(c)

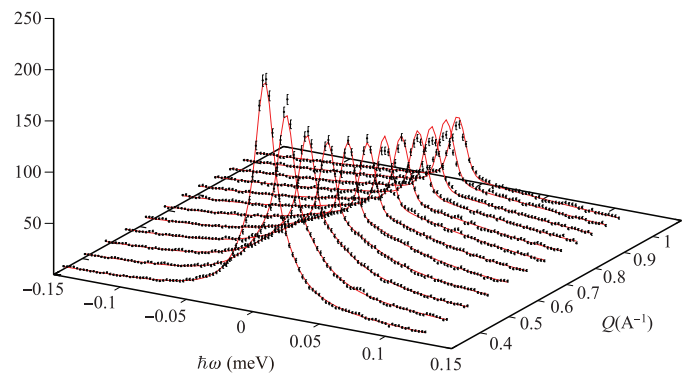

(e)

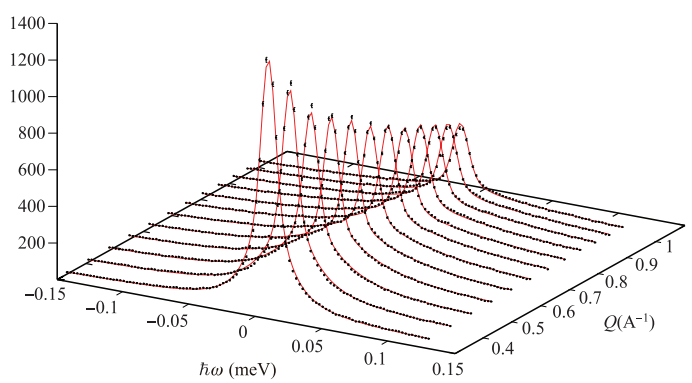

(b)

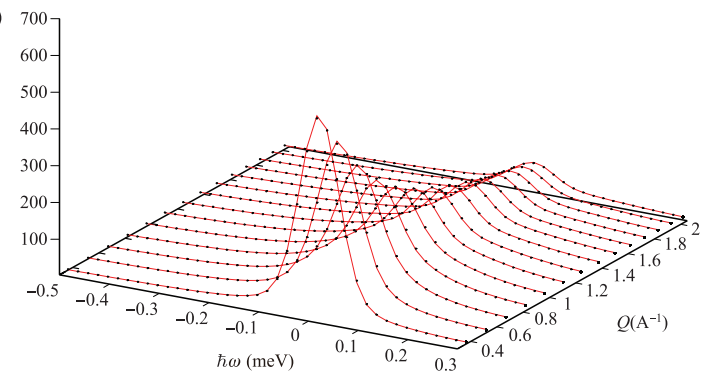

(d)

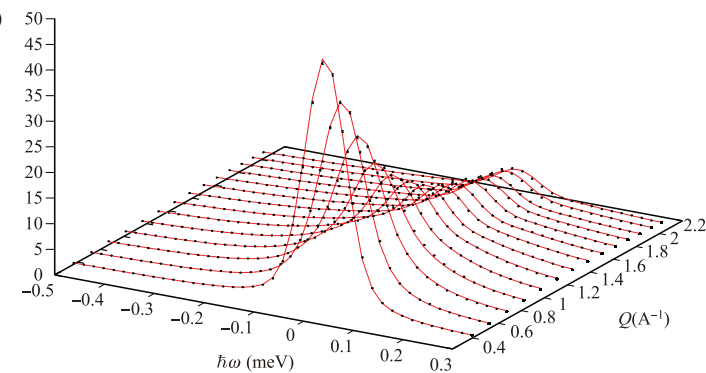

(f)

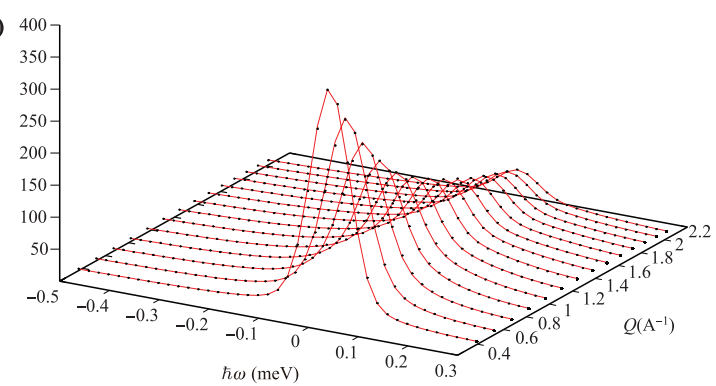

The online version of the original article can be found at https://doi.org/10.1007/s11467-017-0731-5. 